\title{
Epithelial Cyst of the Uvula with Unilateral Complete Cleft Lip and Palate
}

\author{
Young-Bin Kim, Jae-Young Yang, Dae-Ho Leem, Jin-A Baek, Seung-O Ko, Hyo-Keun Shin \\ Department of Oral and Maxillofacial Surgery, School of Dentistry, Chonbuk National University
}

\begin{abstract}
Epithelial cysts are benign epithelium-lined lesions that contain fluid or semisolid material. Most epithelial cysts in the oral cavity occur in the anterior part of the mouth floor. Cysts arising on the uvula in a cleft palate patient are rare. Intraoral examination in a 14-month-old boy with a complete cleft lip and palate revealed a cystic lesion on the right uvula. The lesion was excised and push-back palatorrhaphy with Z-plasty on the uvula was performed. Histopathological examination diagnosed an epithelial cyst. We report a case of an epithelial cyst of uvula in a patient with a unilateral complete cleft lip and palate.
\end{abstract}

Key words: Epithelial cyst, Cleft palate, Uvula, Soft palate

\section{Introduction}

Epithelial cysts are benign lesions with epithelial lining containing fluid or semisolid material. These lesions can be found on any part of the body, although 6.9\% of them appear at head and neck area and only 1.6\% are seen in the oral cavity[1,2]. Most cysts occurring in the oral cavity are located at the anterior part of the mouth floor, and the soft palate or uvula is an unusual site[3-6]. There is no report of an epithelial cyst of the uvula in a cleft palate patient. We present a rare case of an epithelial cyst on the uvula with a cleft lip and palate, with a literature review.

\section{Case Report}

The patient was a 14-month-old male infant with unilat- eral complete cleft lip and palate on the left side, with no other remarkable medical history. He underwent primary cheiloplasty using the triangular flap procedure at the age of 4 months and revisited our clinic for palatorrhaphy. Clinical examination revealed a mucosal bulging on the right uvula with a smooth, yellow-whitish surface (Fig. 1). There were no other pathological findings in the oral cavity.

Under general anesthesia, the cystic lesion on the right uvula was surgically excised for histopathological examination. The Z-plasty was performed to correct the size differences of each uvula. Push-back palatorrhapy was then performed. The excised cystic lesion was separated easily with oval shape measured $4 \times 4 \mathrm{~mm}$ size (Fig. 2).

Microscopic examination of the specimen sections at high magnification revealed small cystic lesions within the

RECEIVED September 13, 2013, ACCEPTED January 10, 2014

Correspondence to Hyo-Keun Shin

Department of Oral and Maxillofacial Surgery, School of Dentistry, Chonbuk National University

567 Baekje-daero, Deokjin-gu, Jeonju 561-756, Korea

Tel: 82-63-250-2113, Fax: 82-63-250-2089, E-mail: hkshin@jbnu.ac.kr

(C) This is an open access article distributed under the terms of the Creative Commons Attribution Non-Commercial License (http://creativecommons. org/licenses/ by-nc/3.0) which permits unrestricted non-commercial use, distribution, and reproduction in any medium, provided the original work is properly cited. 


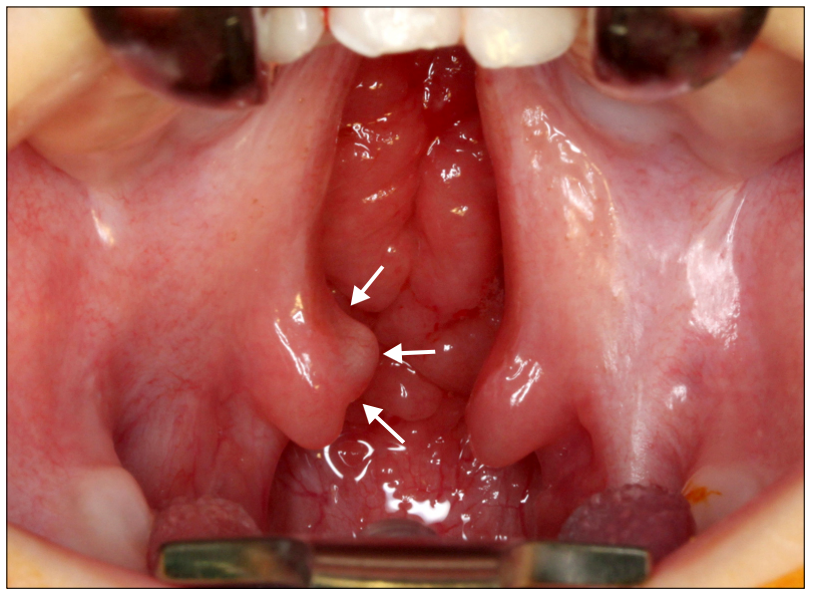

Fig. 1. The intraoperative appearance of the cystic lesion on right side of uvula (arrows).

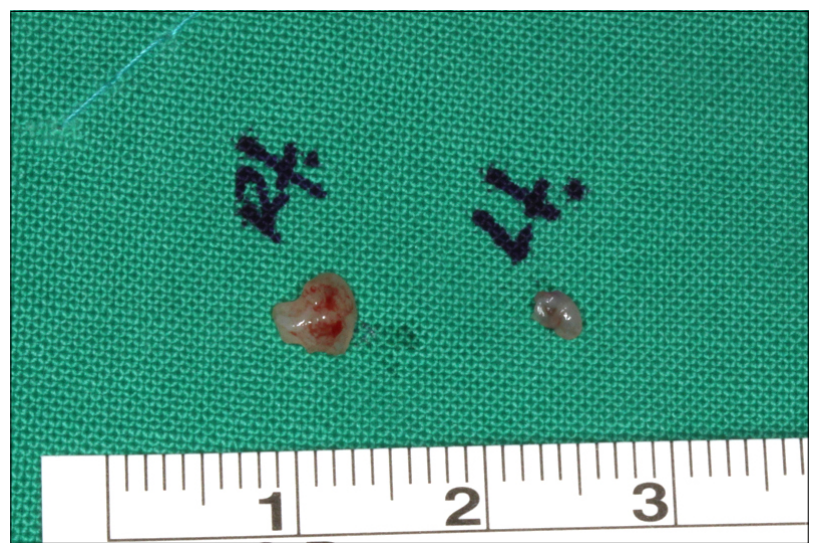

Fig. 2. Specimen. Right side of the uvula shows cystic lesion and left side is normal deepithelization pattern.

surrounding mucosal surface consisted of stratified squamous epithelium and ciliated cuboidal-to-columnar epithelium (Fig. 3). There was no evidence of skin appendages or sweat or sebaceous glands in the cyst.

\section{Discussion}

Epithelial cysts are slowly enlarging painless lesions, either congenital or acquired. The congenital cysts are called epithelial cysts, and the acquired cysts are known as implantation or post traumatic cysts[3]. For differential diagnosis of this type of cystic lesion, epidermal cyst, dermoid cyst, inclusion cyst, branchial cleft cyst, and mucous cyst should be considered, but these lesions can be diagnosed with certainty only by histological examination[5,7-9]. An epithelial cyst in the oral cavity was first reported in 1970[3],

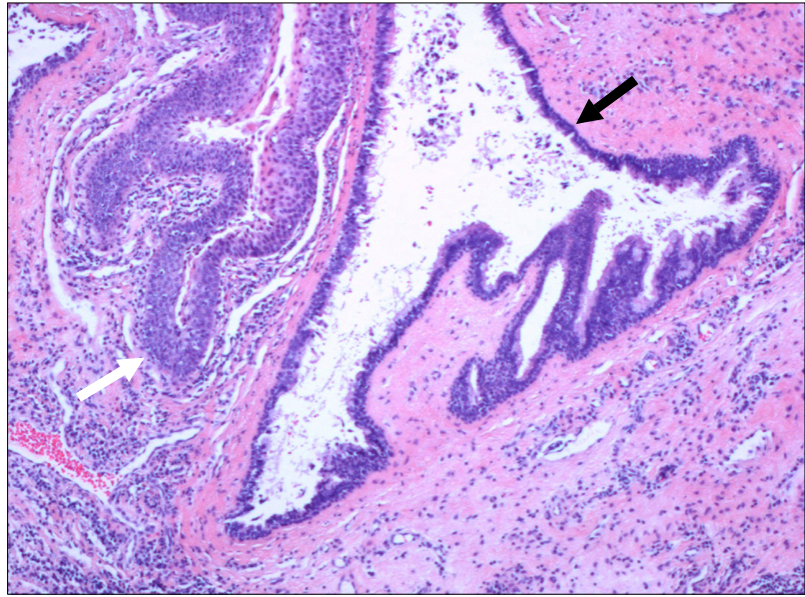

Fig. 3. Microscopic examination. The outer surface (white arrow) and inner surface (black arrow) of the cyst are shown, lined with stratified squamous epithelium and ciliated cuboidal-to-columnar epithelium, respectively $(H \& E, \times 200)$.

and a few epithelial cysts on the soft palate or uvula were reported[4-6,9].

The origin of epithelial cysts is uncertain. However, the most convincing hypothesis is that the cyst originates from ectodermal debris, separated during the midline closure of embryonic fissures[7]. This hypothesis was supported by an experiment that successfully produced a dermoid cyst in the laboratory[10]. Most epithelial cysts seen in the oral cavity, pharynx, and cervical area are presumed to develop from separated ectoderm during the fusion process between the first and second branchial arches. Some of the epidermoid cysts arising in oral cavity can result from the fusion of the lateral processes on either side of the first branchial arch[1,6,7]. Epithelial cysts occurring in the soft palate and uvula probably originate from the fusion of the palatine plates.

Most of the lesions are asymptomatic, but in some cases, enlarged cystic lesions can cause air way obstruction, sonorous respiration, gagging or dysphagia[5,9]. The surgical excision of the epithelial cyst is diagnostic and treatment method at the same time, and no obvious complications have been reported[6,7].

This is an interesting case in which the epithelial cyst was on the uvula, a rare location, with a cleft palate patient. We recommend a careful clinical examination of the soft palate or uvula for patients with cleft palate to detect a cystic lesion at a rare location. 


\section{Acknowledgements}

We thank Professor Nam-Pyo Cho at the Department of Oral Pathology, Chonbuk National University School of Dentistry, for his helpful suggestions in pathologic diagnosis.

\section{References}

1. New GB, Erich JB. Dermoid cyst of the head and neck. Surg Gynecol Obstet 1937;65:48-55.

2. Turetschek K, Hospodka H, Steiner E. Case report: epidermoid cyst of the floor of the mouth: diagnostic imaging by sonography, computed tomography and magnetic resonance imaging. Br J Radiol 1995;68:205-7.

3. Sánchez Torres J, Higa TT. Epidermoidal cysts in the oral cavity. Report of three cases. Oral Surg Oral Med Oral Pathol
1970;30:592-600.

4. Green JD, Neal CL. Dermoid cyst of the soft palate. South Med J 1982;75:1029.

5. Seshul M, Tseng E, Wiatrak BJ, Kelly DR. Isolated epithelial cysts of the uvula in children: a report of three cases. Ann Otol Rhinol Laryngol 1998;107:717-9.

6. Caylakli F, Yavuz H, Bolat F, Ozer F, Ozgirgin N. Epithelial cyst of the soft palate. Int J Pediatr Otorhinolaryngol 2005;69: 545-7.

7. Yoshinari M, Nagayama M. Epidermoid cyst of the uvula: report of a case. J Oral Maxillofac Surg 1986;44:828-9.

8. Jensen JL. Superficial mucoceles of the oral mucosa. Am J Dermatopathol 1990;12:88-92.

9. Mu SC, Sung TC, Yeh ML, Hsu ST, Lin MI, Chen HY. Solitary epithelial cyst of the uvula in the neonate: case reports and review of the literature. Pediatr Emerg Care 2002;18:93-4.

10. Colp R. Dermoid cysts of the floor of the mouth. Surg Gynecol Obstet 1925;40:183-95. 